\title{
Article \\ Separation of Multi-Material Polymer Combinations Produced by Joining Using Pin-like Structures
}

\author{
Michael Wolf* (D) and Dietmar Drummer
}

Citation: Wolf, M.; Drummer, D. Separation of Multi-Material Polymer Combinations Produced by Joining Using Pin-like Structures. J. Manuf. Mater. Process. 2022, 6, 13. https:// doi.org/10.3390/jmmp6010013

Academic Editors: Lucas da Silva, Mohamad El-Zein, Paulo A. F. Martins, Uwe Reisgen and Steven Y. Liang

Received: 2 November 2021

Accepted: 18 January 2022

Published: 19 January 2022

Publisher's Note: MDPI stays neutral with regard to jurisdictional claims in published maps and institutional affiliations.

Copyright: (C) 2022 by the authors. Licensee MDPI, Basel, Switzerland. This article is an open access article distributed under the terms and conditions of the Creative Commons Attribution (CC BY) license (https:// creativecommons.org/licenses/by/ $4.0 /)$.
Institute of Polymer Technology, Friedrich-Alexander-University Erlangen-Nuremberg, 91056 Erlangen, Germany; dietmar.drummer@fau.de

* Correspondence: michael.wolf@fau.de

\begin{abstract}
In industrial applications, multi-material joints are becoming increasingly important to achieve a sustainable and resource-saving production. Not only high mechanical properties during the component use have to be given, but also possibilities to separate the joint after end of life are crucial. The recycling and re-use of the materials plays an increasing role in the process chain. Conventional multi-material joints can be separated by cutting out the joining zone, solvents, or thermal degradation. However, these methods result in a loss of material, damage to the base material, or high energy consumption. Therefore, novel joining methods are desirable, such as the joining using pin-like structures. The potential of this novel method for joining adhesion incompatible materials has been demonstrated in previous studies. This paper studies the separability of these connections. Therefore, joints between polyamide 66 (PA66) and polypropylene (PP) as well as PA66 and polymethylmethacrylate (PMMA) are investigated by means of thermal separation and shredding with subsequent sorting using the density difference of the materials. The separated components were investigated by analytical methods (including dissolution tests, viscosity number analysis, and Fourier-transform infrared spectroscopy) with respect to varietal purity and possible degradation effects. It could be shown that shredding allows a complete separation of the multi-material joint into its individual components without material residues or material loss. For thermal separation, material residues of PP or PMMA could be detected in the pin gaps of the PA66. For both separation methods, an influence on the base materials due to degradation effects could be excluded. It can be stated that joining using pin-like structures in vibration welding technology offers a sustainable production of multi-material joints with high recyclability.
\end{abstract}

Keywords: joining; pin-like structures; multi-material; separation; disassembling; recycling

\section{Introduction}

Multi-material connections allow a more efficient use of material-specific advantages by combining different materials and material types [1]. This enables the achievement of local component properties (e.g., mechanical, thermal or chemical resistance, optical characteristics, etc.) which are adapted to the individual application.

For the production of multi-material polymer connections, joining processes are necessary, which ensure not only high mechanical properties but also the possibility to separate the connection after the end of life. Recycling and the re-use of the base materials is playing a decisive role in the process chain. For example, in the automotive industry, 95\% of the components used must be recyclable by 2015 [2].

With the exception of mechanical fasteners, which however have limitations in their applications (e.g., complex design and limited geometric freedom of the joining zone), polymer-polymer joints can be separated only with great effort. For welded joints, a separation of the base materials is generally only feasible by cutting out the joining zone due to the predominant adhesive bond. This results in a significant loss of material and 
can also be very complex depending on the component geometry. In addition, the production of multi-material joints is very limited for conventional welding technologies, as can be seen in so-called compatibility matrices [3]. In addition to an adhesion compatibility, similar melting temperatures as well as similar viscosity at the joining temperature are required [4]. By means of gluing, the range of polymer combinations can be greatly increased. However, adhesive bonds are limited by the necessary time- and cost-intensive surface pre-treatment $[5,6]$ and by the contained health-endangering ingredients. In addition, separation by end of life is only possible to a limited extent in these applications as well.

After end-of-life, multi-material assemblies are often energetically recycled by incineration. In this way, a part of the energy can be recovered [7]. However, this type of recycling is not very efficient and generates pollution [7]. In order to reuse the base materials, adhesive bonds can be debonded by mechanical separation [8], optionally with additional energy support by e.g., ultrasound [9], or by the use of solvents, thermal degradation, or cutting out the bond zone [10]. Solvents require a complex process control. In addition, they can cause chemical reactions in the base material, which negatively change the material properties. Thermal degradation can also lead to a damage of the base material and has disadvantages such as high energy consumption and the partial emission of toxic fumes. For these reasons, adhesive joints are often separated by cutting out the joint zone, and the resulting material loss must be accepted.

As shown, there is currently no adequate method of separating adhesive joints; current investigations are dealing with the adaption of the adhesive layers in order to enable better separation. By filling the adhesive layer with e.g., ferromagnetic nanoparticles [11] or graphite nanoparticles [12], this layer can be heated locally by means of an electromagnetic field or high-frequency radiation. Thus, a local separation can be achieved, which usually also results in a reduced energy requirement. Nevertheless, adhesive residues remain in the joining zone, which prevent a complete sorting purity. In addition, the modified adhesives must be specifically adapted to the application and the separation process, which limits their field of application. Similarly, thermally expandable additives or chemical foaming agents are used in some applications [8]. The expansion in the bond zone results in a separation of the joint. However, pure separation is not possible, and additives must be specifically adapted to the conditions of use.

In summary, it can be stated that current joining processes have limitations in terms of their ability to be separated after end of life. Therefore, novel joining methods are necessary, which on the one hand allow the production of multi-material connections and on the other hand enable a separation of the different base materials without or with only very low material loss. Such a process is the joining by means of pin-like structures in vibration welding. This form-fit joining process allows the combination of incompatible polymers and thus the generation of local part properties adapted to the application. In addition, it offers potential for the subsequent separation of the individual materials, since no adhesive bond is created. Within this paper, this potential for pure separation is to be analyzed. Two different separation methods are used. On the one hand, the separation takes place by thermal debonding of the components. On the other hand, shredding of the joint with subsequent sorting of the single materials by using the density differences is investigated. Both separation methods are subsequently evaluated by analytical analysis with regard to their purity and occurring material degradation.

\section{Material and Methods}

\subsection{Material}

For the study, the commercially available polyamide 66 (PA66), type Ultramid A3K (BASF AG, Ludwigshafen, Germany), was used as structured-partner. As bonding-partners, polypropylene (PP), type Sabic 505P (Sabic Europe B.V., Sittard, The Netherlands) as well as polymethylmethacrylate (PMMA), type Plexiglas 7N (Evonik Industries AG, Essen, Germany) were used. 
For all materials, injection-molded plates with dimensions of $115 \mathrm{~mm} \times 115 \mathrm{~mm} \times$ $4 \mathrm{~mm}$ were produced. Therefore, an injection-molding machine of the type Allrounder 370V / 800-315 (Arburg GmbH \& Co. KG, Lossburg, Germany) was used. The PA66 and PMMA granulate was dried before processing according to manufacturer specifications $\left(80{ }^{\circ} \mathrm{C}, 4 \mathrm{~h}\right)$. The main injection-molding processing parameters are listed in Table 1 . By means of milling, weld plates with dimensions of $52 \mathrm{~mm} \times 50 \mathrm{~mm} \times 4 \mathrm{~mm}$ were prepared out of the injection-molded plates. These specimens were used to produce the adhesion incompatible butt joints in joining by the use of pin-like structures.

Table 1. Main injection-molding parameters.

\begin{tabular}{cccc}
\hline Material & PA66 & PP & PMMA \\
\hline Melt temperature $\left[{ }^{\circ} \mathrm{C}\right]$ & 290 & 250 & 230 \\
Mold temperature $\left[{ }^{\circ} \mathrm{C}\right]$ & 70 & 60 & 60 \\
Injection speed $[\mathrm{mm} / \mathrm{s}]$ & 50 & 60 & 60 \\
Holding pressure $[\mathrm{bar}]$ & 450 & 250 & 450 \\
Holding time $[\mathrm{s}]$ & 30 & 40 & 25 \\
\hline
\end{tabular}

\subsection{Joining by Use of Pin-Like Structures}

The joining using pin-like structures in the vibration welding process is a form-fit joining process and can be divided into two steps: the structuring process and the joining process, as shown in Figure 1. Both steps are carried out with a laboratory vibration welding machine of the type Branson M-112 HR (Branson Ultraschall, EMERSON Technologies $\mathrm{GmbH} \&$ Co. KG, Dietzenbach, Germany), while no surface preparation is necessary. This enables a simple and cost-efficient production of incompatible multi-material joints.

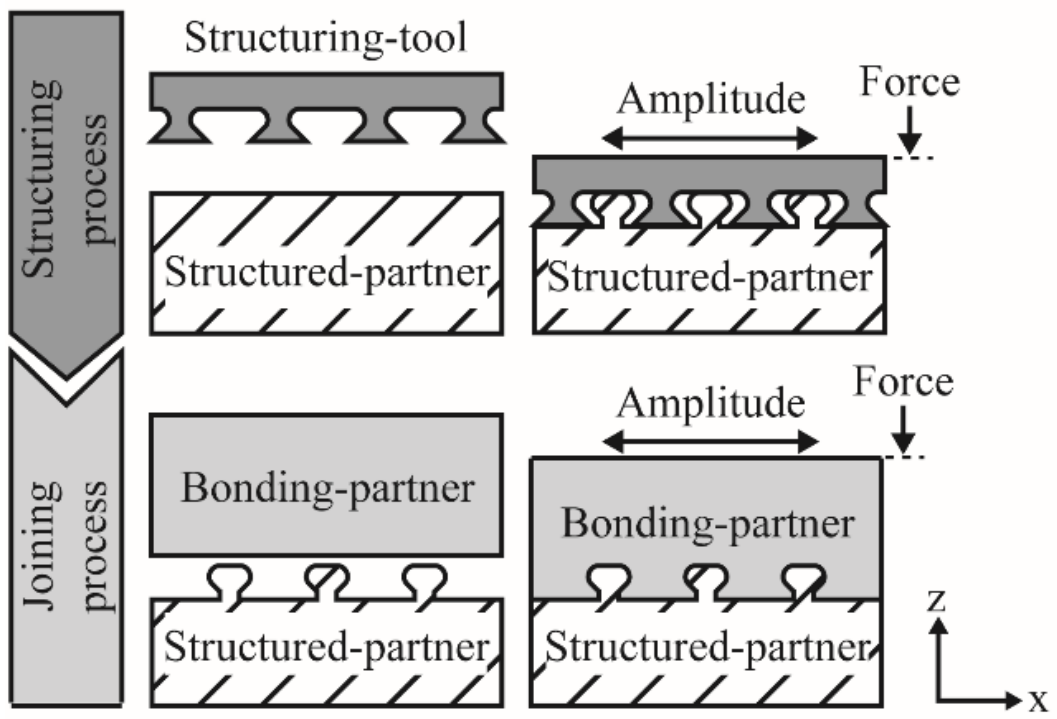

Figure 1. Process schema of the form-fit joining using pin-like structures in the vibration welding process [13].

In the first step, pin-like structures are introduced into the structured-partner. Therefore, a structuring tool made of steel (S235JR) is used. A relative friction movement with amplitude a and force $\mathrm{F}$ between the tool and the structured-partner leads to melting of the structured-partner and filling of the tool structures. The pin structures generated can theoretically cover a wide range of size and shape. In previous studies, two different types of pin shapes (trapezoidal, mushroom-like) were mainly investigated experimentally as well as numerically $[14,15]$. Here, the pin-like structures were macroscopic with a pin-height of about $2 \mathrm{~mm}$. In the second step, a relative friction movement takes place between the structured-partner and the bonding-partner. The bonding-partner melts (semi-crystalline) 
or softens (amorphous). By filling the pin-like structures created in the structured-partner, the form-fit multi-material connection is generated. To avoid a deformation of the existing pin structures during the joining step, the bonding-partner should be flowable in a temperature range in which the structure-partner does not melt. In the case of PA66 as a structured-partner, this could be achieved in previous investigations using, for example, PE, PP, or PMMA as a bonding-partner [13,16]. A detailed description of the form-fit joining process using pin-like structures is shown in earlier investigations [16].

In addition to the functionality and the high potential for joining incompatible semicrystalline thermoplastics $[13,16]$ as well as for joining incompatible semi-crystalline and amorphous thermoplastics [16], first process correlations have been developed. The investigation of the thermomechanical properties shows a stability of the pin-like structures in the PA66 during the joining process for the material combination investigated in this study [16]. Further investigations address the influence of the used structuring-tool geometry on the generation of the pin-like structures, their filling behavior during the joining process, as well as the resulting bond properties [14], and they allow first design criteria for the geometry of the pin-like structure in dependence on the used material combination [15].

It can be summarized that strong connections between incompatible polymer combinations can be produced using pin-like structures. A single-origin separation of these joints should theoretically be possible due to the non-existing material interactions in the joining zone. Findings in this context are to be developed within the framework of this paper. For this purpose, butt joints were made, as shown in Figure 2. A structuring-tool with mushroom-like structures was used for the structuring process. The process parameters of the structuring as well as joining step are listed in Table 2. Before the vibration welding tests, the PA66 specimens were dried in a vacuum oven at $70{ }^{\circ} \mathrm{C}$ until no further weight loss occurs.

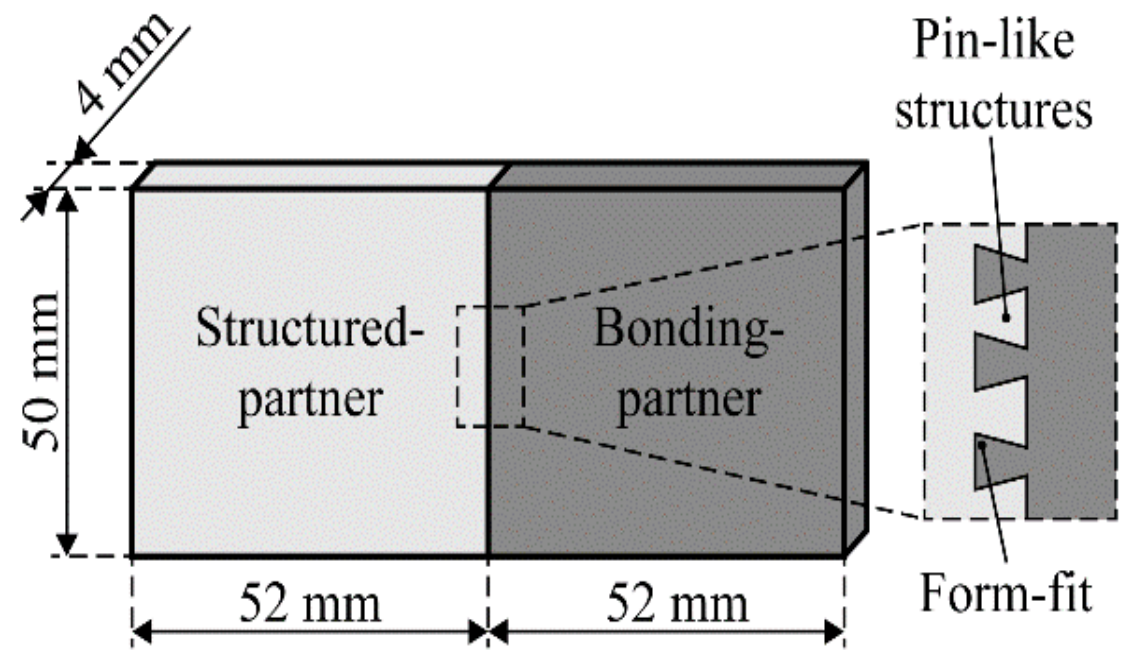

Figure 2. Form-fit multi-material butt joint using pin-like structures [14].

Table 2. Used process parameters.

\begin{tabular}{ccc}
\hline Process Steps & Structuring & Joining \\
\hline Frequency [Hz] & 235 & 235 \\
Amplitude [mm] & 0.7 & 0.7 \\
Force [N] & 600 & 400 \\
Path [mm] & 1.2 & 1.5 \\
\hline
\end{tabular}

The structuring-tool used as well as the process parameters and material combinations are identical to a previous study [14]. In this investigation, the generated pin-like structures were optically analyzed before and after the joining step, and the mechanical 
bond properties were tested. It was shown that a deformation of the pin-like structures occurs due to the extraction movement of the tool, but no influence on the structures takes place during the joining process. Bond strengths (in relation to the smallest cavity width between the pin-like structures) of approximately $25 \mathrm{~N} / \mathrm{mm}^{2}$ (PA66-PP) and approximately $67 \mathrm{~N} / \mathrm{mm}^{2}$ (PA66-PMMA) were achieved with these multi-material connections. Due to the identical process route, the joints produced during this study do not differ from those of the previous investigation. In the following, the focus is on the separability of the produced multi-material joint, and the bond properties can be found in [14].

\subsection{Separation Processes}

The separation of the multi-material combinations was carried out via two process routes. On the one hand, the separation took place by shredding, and on the other hand, thermal separation was used.

The shredding tests were carried out using a Rapid 150 granulator (Rapid Granulator AB, Bredaryd, Sweden) with a sieve width of $5 \mathrm{~mm}$. For both multi-material combinations, five joints were separated. The shredded material was collected and subsequently fractionated in water. For this purpose, the density of the water was adjusted using sodium chloride so that a fractionation of the different base materials can be achieved. The difference in density between PA66 with $1.13 \mathrm{~g} / \mathrm{cm}^{3}$ [17] and PP with $0.905 \mathrm{~g} / \mathrm{cm}^{3}$ [18] allows the fractionation in water without further modification. In this case, the density of the water was $0.99 \mathrm{~g} / \mathrm{cm}^{3}$. Due to the minor density difference for the combination between PA66 and PMMA (density of $1.19 \mathrm{~g} / \mathrm{cm}^{3}$ ) [19], the density of the water was adjusted by sodium chloride to a value of $1.15 \mathrm{~g} / \mathrm{cm}^{3}$. Thus, a fractionation of the single base materials shall also be possible.

In addition to separation by shredding, a thermal separation of the multi-material bond was investigated. Therefore, the joining area was heated to a material-dependent temperature, determined by Differential Scanning Calorimetry (DSC) measurements, using a short-wave infrared radiator (Optron $\mathrm{GmbH}$, Garbsen, Germany). The distance between the radiator and the specimen was defined in preliminary tests so that after a heating time of $300 \mathrm{~s}$ with $100 \%$ power, the required temperature was reached in the joining zone. For both multi-material combinations, this distance is $130 \mathrm{~mm}$. The experimental setup is shown schematically in Figure 3. Six joints per material combination were separated. Five of these were used for the further investigations; the resulting temperature in the joining zone during the heating process was measured on one joint. Therefore, a thermocouple type $\mathrm{K}$ was placed in the joining zone in the middle of the bonding-partner, and the temperature was recorded. The maximum temperature after a heating time of $300 \mathrm{~s}$ was evaluated.

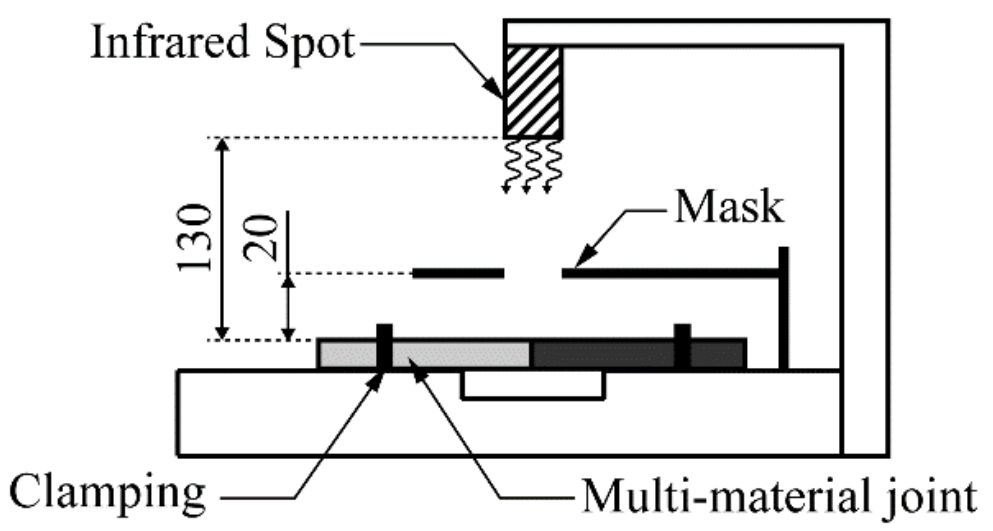

Figure 3. Setup for thermal separation by heating with IR spot. 


\subsection{Analyzing Methods}

\subsubsection{Differential Scanning Calorimetry (DSC)}

To analyze the softening and melting behavior of the used materials, DSC measurements were conducted, and the second heating was evaluated. For the measurements, a device of the type DSC Q 2000 (TA Instruments, New Castle, DE, USA) was used. The heating rate was $10 \mathrm{~K} / \mathrm{min}$ in a nitrogen atmosphere with specimen weights of approximately 3-5 mg. The specimens were prepared form the joining zone of the weld plates.

\subsubsection{Rotational Rheometry}

The rheological behavior of the bonding-partners was characterized by rotational rheometry using a rheometer of the type AR 2000 (TA Instruments, New Castle, DE, USA). Plate-to-plate measurements were performed with specimens of $25 \mathrm{~mm}$ diameter. The test frequency was $1 \mathrm{~Hz}$ at an angular frequency of $6.28 \mathrm{rad} / \mathrm{s}$ and a heating rate of $3 \mathrm{~K} / \mathrm{min}$. The temperature-dependent complex viscosity was evaluated. This should on the one hand confirm the temperature range determined by DSC and on the other hand allow explanations of possible adhesion after thermal separation.

\subsubsection{Surface Tension}

The surface tension of the materials was determined on the welding plates by means of contact angle measurement with a device of type OCA20 (Data Physics Instruments $\mathrm{GmbH}$, Filderstadt, Germany). Water, glycerol, formamide, diiodomethane, ethylene glycol, dimethyl sulfoxide, benzyl alcohol, and N,N-dimethyl formamide were used as test liquids. The evaluation of the surface tension and the disperse and polar fractions was carried out according to Owens-Wendt-Rabel-Kälble (OWRK) [20] as well as Wu [21]. The surface tension and especially the polar fractions may explain the material residuals after the separation.

In addition, the surface tension in the molten state was determined for PP and PMMA. The measuring temperature was $170{ }^{\circ} \mathrm{C}$ for PP and $230^{\circ} \mathrm{C}$ for PMMA. This corresponds closely to the temperatures occurring during the joining step [10]. The evaluation of the melt droplet was carried out according to Laplace-Young.

\subsubsection{Viscosity Number}

With the help of the viscosity number, the degradation or aging effects of the material due to the separation process shall be detected. The viscosity number was analyzed according to DIN EN ISO 1628-3 (PP) [22], 1628-6 (PMMA) [23], and 307 (PA66) [24] with an Ubbelohde viscometer. The dissolvers were selected according to the polymer. For PA66, $97 \% \mathrm{H}_{2} \mathrm{SO}_{4}$ with a concentration of $0.005 \mathrm{~g} / \mathrm{mL}$ was used. Chloroform with a concentration of $0.0026 \mathrm{~g} / \mathrm{mL}$ was used for PMMA, and a decalin-irganox solution with a concentration of $0.001 \mathrm{~g} / \mathrm{mL}$ was used for PP. For PP, the dissolution took place in an oven at $150{ }^{\circ} \mathrm{C}$. The measuring temperature was $25^{\circ} \mathrm{C}$ for PA66 as well as PMMA and $135^{\circ} \mathrm{C}$ for PP. The PA66 and the PMMA were dried at $70{ }^{\circ} \mathrm{C}$ before the measurements. The samples were taken from the base material (before the joining process) and from the joining zone of the separated joints. In the joining zone, the highest stress occurs on the material. The possible degradation effects are the greatest here.

\subsubsection{Single Material Dissolution}

Dissolution tests were carried out to characterize possible material residues after the separation processes by shredding. The samples of the shredded bonds were taken after the separation in water with sample quantities of approximately $10 \mathrm{~g}$. The sample quantity was taken randomly. The solvents used were the same as for the determination of the viscosity number. 


\subsubsection{Fourier-Transform Infrared Spectroscopy (FTIR)}

FTIR measurements were conducted to detect possible material residues in the cavities between the pin-like structures after the thermal separation. An FTIR of the type Nicolet 6700 (Thermo Fisher Scientific Inc., Waltham, MA, USA) was used. The analysis was carried out for the PA66-PP and PA66-PMMA combination. Therefore, the structured-partner was embedded in cold-curing epoxy resin. Then, thin sections with a thickness of $10 \mu \mathrm{m}$ were prepared over the pin height, as shown schematically in Figure 4a. A prepared thin section is shown in Figure 4b. In addition to the analysis of the structured-partner, characterizations of the three base materials were conducted. These were used to identify material-specific bands for a subsequent material detection.

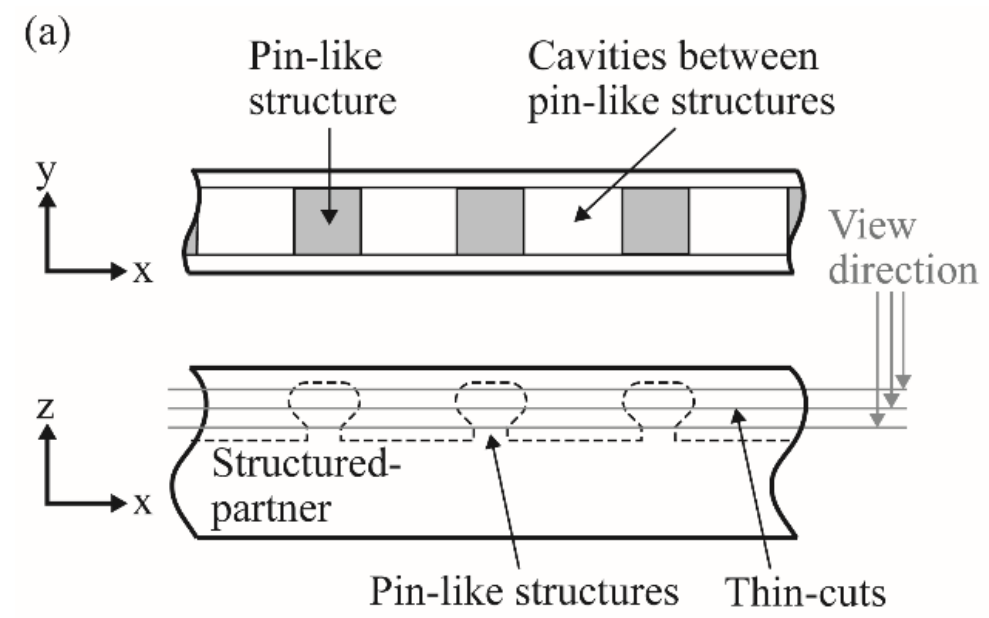

(b)

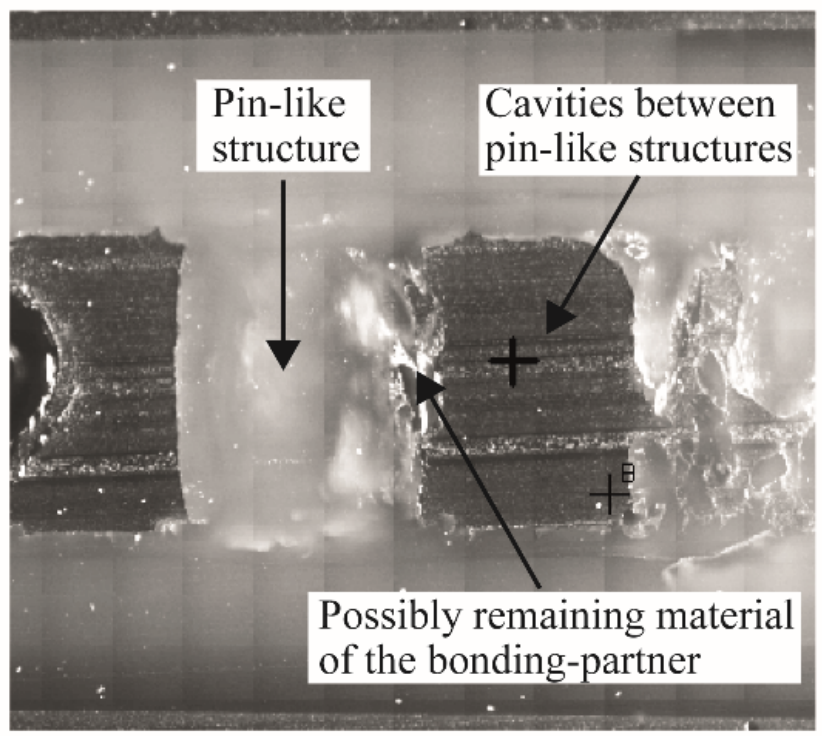

Figure 4. Method for characterization of material residues at the structured-partner after thermal separation using FTIR: (a) schematic illustration of sample preparation, (b) prepared thin-cut for FTIR analysis.

\section{Result and Discussion}

\subsection{Base Material Characterization}

\subsubsection{Thermal Properties}

The thermal properties of the materials were analyzed by DSC. The heating behavior of the samples is shown in Figure 5a. The semi-crystalline materials PP and PA66 show a clear endothermic melt peak during the heating process. The melt peak temperature is $162{ }^{\circ} \mathrm{C}$ for PP and $262{ }^{\circ} \mathrm{C}$ for PA66. Softening, and thus beginning of the flow of the 
materials takes place from an onset temperature of approximately $110^{\circ} \mathrm{C}(\mathrm{PP})$ and $230{ }^{\circ} \mathrm{C}$ (PA66). The glass transition area of the amorphous PMMA is in the range of $104-113{ }^{\circ} \mathrm{C}$, with a midpoint at $109{ }^{\circ} \mathrm{C}$. Flow occurs for amorphous materials with exceeding of the glass transition, whereby the flowability increases with increasing temperature.

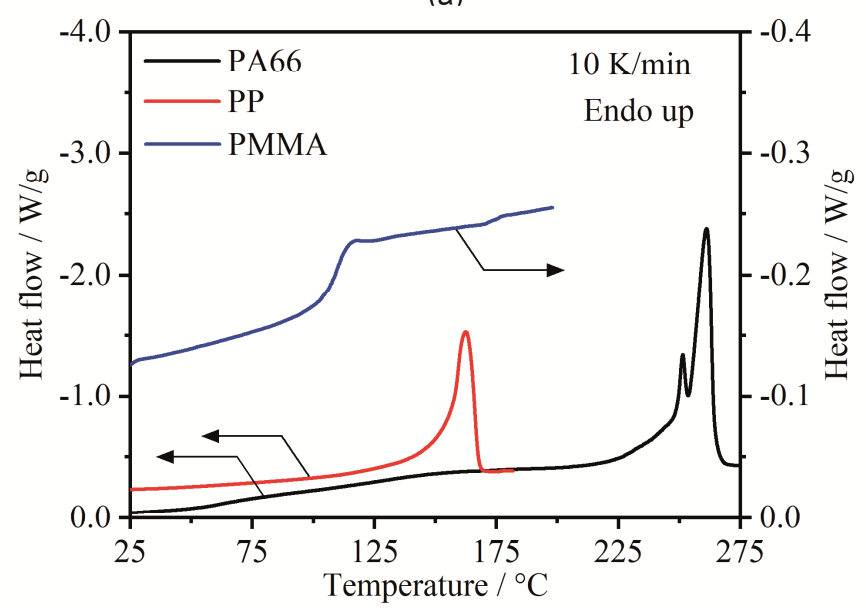

(b)

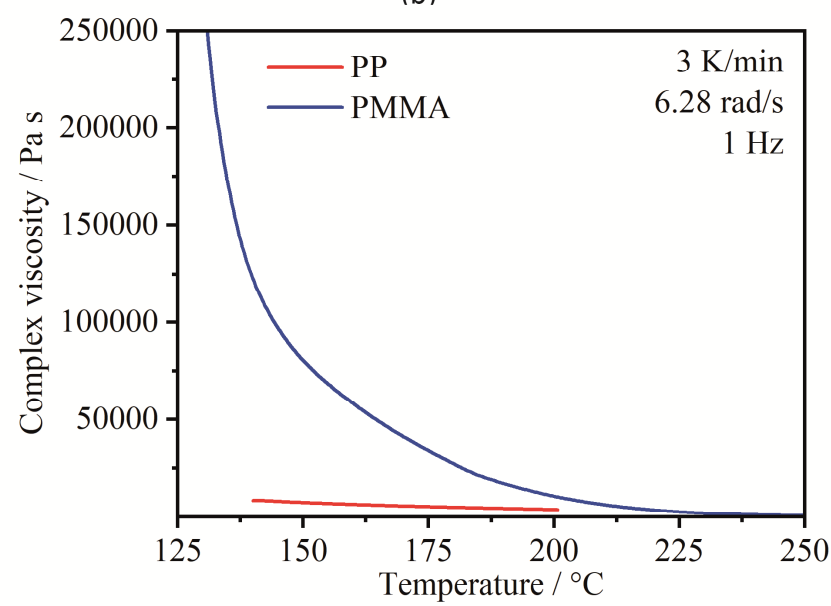

Figure 5. Thermal characterization of the base materials: (a) melting behavior, (b) rheological behavior.

To enable thermal separation of the multi-material bonds, the joining zone must be heated to temperatures at which the bonding-partner begins to flow. The structured-partner, on the other hand, should not soften in order to allow the bonding-partner to be extracted from the structures, ideally without adhesion. As the DSC investigations show, the melting or softening temperature of the bonding-partners should be sufficiently far below the melting onset temperature of the structured-partner. For the PA66-PP joint, the joining zone should be heated to a temperature of between 160 and $220^{\circ} \mathrm{C}$; the PA66-PMMA connection to a temperature should be approximately $120-220{ }^{\circ} \mathrm{C}$.

The rheological behavior of the bonding-partners as a function of the temperature is shown in Figure 5b. The complex viscosity for PP shows a very low level over the entire measuring range between 140 and $200{ }^{\circ} \mathrm{C}$. Consequently, the temperature range defined by DSC (above $160^{\circ} \mathrm{C}$ ) should allow a thermal separation of the PA66-PP multi-material combination. The situation is different for PMMA as a bonding-partner. Here, a clear decrease in viscosity occurs mainly at temperatures between 130 and $150{ }^{\circ} \mathrm{C}$. Therefore, the joining area should be heated to temperatures of at least 135 to $140{ }^{\circ} \mathrm{C}$ in order to ensure sufficient thermal separation. Finally, it can be stated that the viscosity in the relevant temperature range for thermal separation is lower for PP than for PMMA.

\subsubsection{Surface Tension}

The surface tension can hinder the separation of the multi-material connection, even in the case of adhesion-incompatible materials. Especially for the thermal separation, a full separation can be impeded due to the adhesion forces between the partners caused by their surface energy. For separation by shredding, no significant influence by surface tension is expected.

The results of the surface tension analysis are summarized in Table 3. It can be seen that the surface energy of PA66 and PMMA as solids is in a similar range. The polar fractions of the surface energy are also very similar. An equal polarity is beneficial for a specific adhesion between the joining partners [5,6]. PP shows a lower surface energy and a significantly reduced polar fraction. Due to the heating during thermal separation, the surface energy of the molten material was also evaluated for the bonding-partner. In comparison to the solid, it is lower. However, it can be seen that the difference between PA66-PMMA is smaller than that between PA66-PP. For this reason, it is assumed that the 
specific adhesion between PA66 and PMMA is higher, and therefore, more residues may adhere to the PA66 after thermal separation than for PA66-PP.

Table 3. Surface energy and polar fraction of the materials in $[\mathrm{mN} / \mathrm{m}]$.

\begin{tabular}{|c|c|c|c|c|c|}
\hline \multirow{3}{*}{ Materials } & \multicolumn{4}{|c|}{$\begin{array}{c}\text { Solid Materials } \\
\text { (Contact Angle Measurement) }\end{array}$} & \multirow{3}{*}{$\begin{array}{c}\text { Melt } \\
\text { (Pendant Drop Method) } \\
\text { Surface Energy }\end{array}$} \\
\hline & \multicolumn{2}{|c|}{ Wu } & \multicolumn{2}{|c|}{ OWRK } & \\
\hline & Surface Energy & Polar Fraction & Surface Energy & Polar Fraction & \\
\hline PA66 & 38.1 & 18.6 & 34.9 & 16.8 & - \\
\hline PP & 26.9 & 10.6 & 23.3 & 6.1 & $19.2 \pm 0.4\left(\right.$ at $\left.170{ }^{\circ} \mathrm{C}\right)$ \\
\hline PMMA & 40.1 & 15.1 & 36.4 & 12.8 & $24.6 \pm 0.5\left(\right.$ at $\left.230^{\circ} \mathrm{C}\right)$ \\
\hline
\end{tabular}

\subsection{Separation by Shredding}

Both multi-material combinations can be separated by shredding and subsequent fractioning in water by means of the existing density difference. Figure 6 shows an exemplary image of the fractionated components of the multi-material combination PA66-PMMA after shredding. The dissolution tests carried out after fractionation showed no polymer residues of the corresponding joining partners. The randomly taken samples were completely dissolved. However, material residues of the joining partner would exist merely in the area of the joining zone, which takes up only about $4 \%$ of the volume of the sample. Since no residues were detectable in any of the solution tests, a pure separation of the materials can be assumed. Nevertheless, material residues cannot be completely ruled out. For this reason, additional weighing tests were carried out. Here, no deviation between the initial samples weight and the shredded components weight could be detected, either. The assumption of good separability by shredding shall be further verified by solution tests with larger sample quantities taken directly from the bond area.

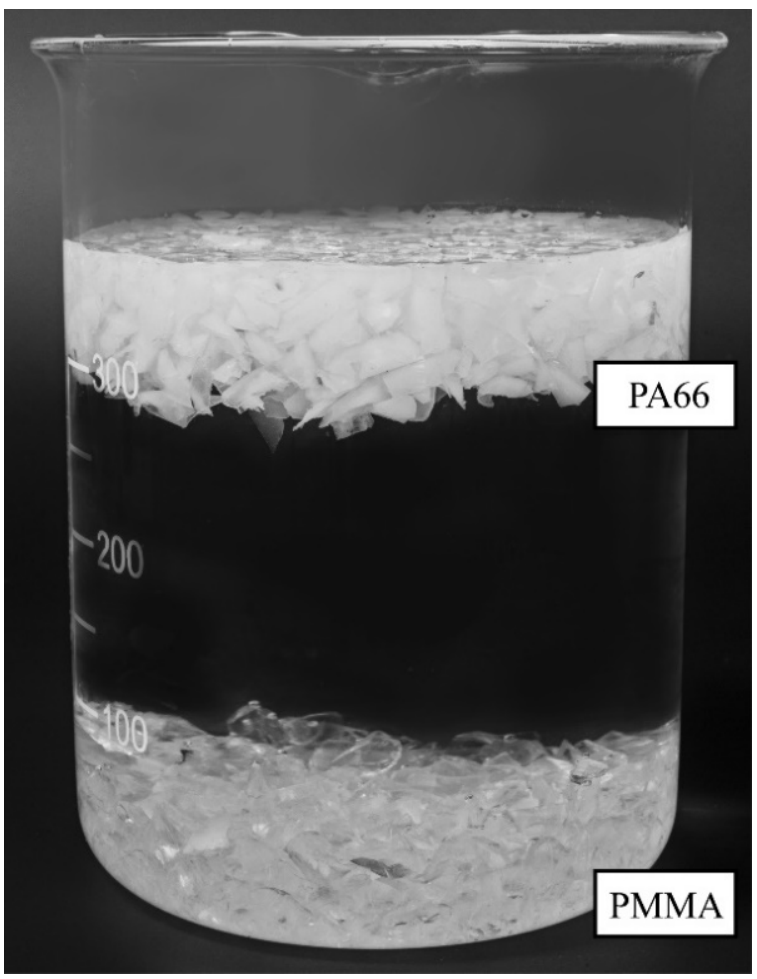

Figure 6. Exemplary picture of the fractionation by means of density differences.

\subsection{Thermal Separation}

The thermal separation of the multi-material joints could be realized for both bondingpartners. After a heating time of $300 \mathrm{~s}$, a joining zone temperature of $187^{\circ} \mathrm{C}$ was achieved 
for PP and $134^{\circ} \mathrm{C}$ was achieved for PMMA as the bonding-partner. Thus, the temperature was within the previously defined temperature range. Due to the temperature above the melt peak temperature of PP and above the softening temperature of PMMA, a flowability of the bonding-partner can be assumed. The melt onset temperature of PA66 (approximately $230{ }^{\circ} \mathrm{C}$ ) was not reached, so softening of the structured-partner does not occur.

FTIR investigations were carried out after separation to detect material adhesion of the bonding-partner in the cavities between the pin-like structures of the PA66. First, the three base materials were analyzed to detect material-specific band peaks for the respective material, which are not present in the joining partner. This enables a clear assignment of the materials. This analysis of the base materials revealed material-specific bands at a wavenumber of $1536 \mathrm{~cm}^{-1}$ for PA66, $973 \mathrm{~cm}^{-1}$ and $998 \mathrm{~cm}^{-1}$ for PP, as well as $1145 \mathrm{~cm}^{-1}$ and $1726 \mathrm{~cm}^{-1}$ for PMMA. Using these material-specific wavenumbers, the prepared thin sections of the structured-partner were analyzed. Figures 7 and 8 show exemplary results of the FTIR analysis for thin sections taken at a middle pin height. The evaluation is representative for the entire pin height, with exception of the pin head area. In the pin head area, no adhesion of the bonding-partner can be identified. For the multi-material combination PA66-PP, as shown in Figure 7, residues of PP were detected in the pin gap next to the PA66 pin. Both PP-typical bands show a deflection in the same sample area. A similar result was obtained for the PA66-PMMA combination, Figure 8. However, the band height for PMMA is clearly higher than for PP. Thus, the PMMA residues are qualitatively bigger than those of PP. This behavior can be seen over the entire sample height.

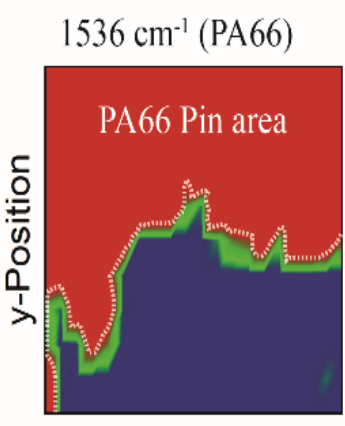

x-Position

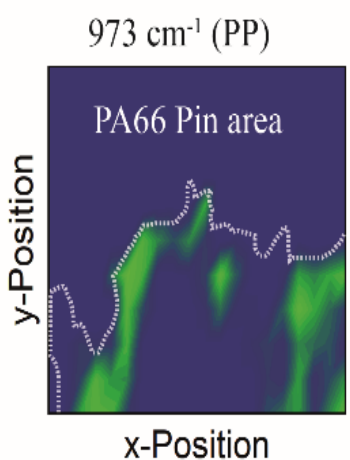

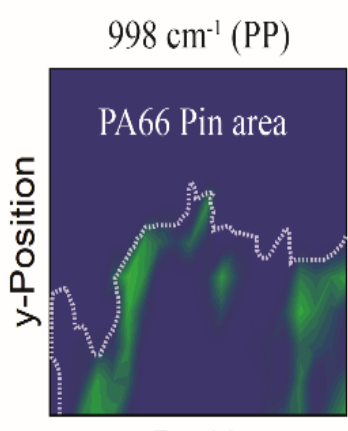
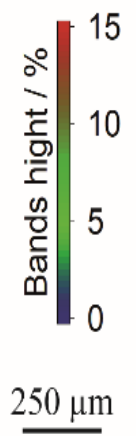

Figure 7. Material detection by FTIR for PA66-PP joint at a thin cut of the structured-partner (PA66) in the area of the cavity between two pin-like structures.
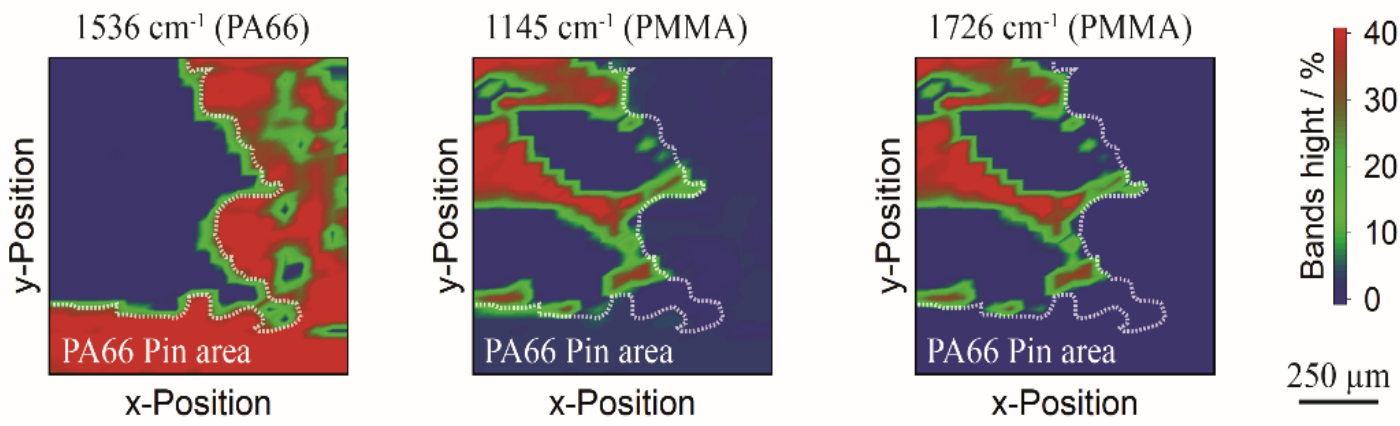

Figure 8. Material detection by FTIR for PA66-PMMA joint at thin cut of the structured-partner (PA66) in the area of the cavity between two pin-like structures.

The increased residues for PMMA, compared to PP, may on the one hand be explained by the viscosity of the bonding-partner during thermal separation. The resulting viscosity of PMMA is about 20 times higher than that of PP. This means that the flowability is lower and the melt stiffness is increased, which can make extraction more difficult. Future investi- 
gations shall be carried out with heating the joining area of the PA66-PMMA connection to approximately $210{ }^{\circ} \mathrm{C}$. This will result in a similar viscosity of the PMMA as for PP, allowing the influence of the viscosity on the separability to be evaluated in more detail. On the other hand, the surface tension can influence the separability. PMMA has a more similar surface energy to PA66 than PP does. In addition, PMMA has a higher number of polar fractions. Therefore, it is assumed that a higher share of specific adhesion can occur between PA66 and PMMA than for the combination between PA66 and PP.

\subsection{Material Degradation}

In order to ensure the subsequent usability of the raw materials for technical components, material degradation during separation must be excluded. Figure 9 shows the viscosity number of the raw materials before and after separation by shredding as well as thermal separation. On the one hand, the bonding-partner (column 2: PP, column 3: PMMA) is analyzed for both separation processes, and on the other hand, the degradation of the structured-partner PA66 (column 1) is characterized. For the structured-partner, a differentiation of the material combination with the respective bonding-partner (indicated in Figure 9 by "with bonding-partner") was also taken into account. Based on these results, no material degradation could be detected during either separation process.

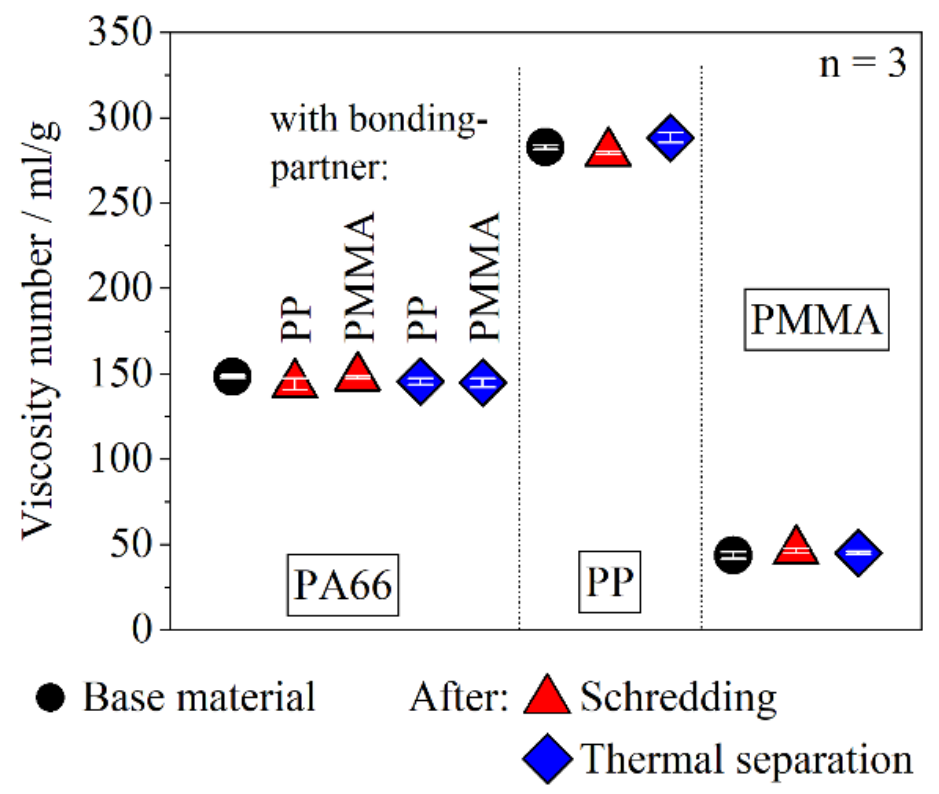

Figure 9. Material degradation after separation of the multi-material bond.

\section{Conclusions}

The investigations show that joining using pin-like structures not only extends the spectrum of possible material combinations but also enables the multi-material bond to be separated into its basic components. Thus, the novel joining process offers an efficient and resource-saving method for the production of assemblies with high recyclability. The evaluation of the two separation methods used shows that shredding allows a separation of the multi-material joint into its individual materials. Residues or material losses are not observed. However, this still needs to be validated with larger sample quantities. For thermal separation, material residues of PP or PMMA could be detected in the pin gaps of the PA66. The reason for the increased residues for PMMA is assumed to be on the one hand the resulting viscosity in the temperature area during thermal separation and on the other hand an increased specific adhesion. For both separation methods, an influence on the base materials due to degradation effects could be excluded. Due to the simple process, the lower energy demand, as well as the achievable separation quality, shredding with subsequent sorting is expected to be preferred in most industrial applications. If 
the difference is sufficient, separation can be carried out with the help of the material density, e.g., in water. Alternatively, other sorting methods would be necessary, for example optical systems.

In addition to the analysis of the viscosity influence, future investigations should address the specific design of the pin-like structures. This shall ensure a sufficient bond quality during the use but at the same time enable full separation after the end of the product life cycle. In the case of thermal separation, specific surface coatings of the pinlike structures could lead to a reduction or even avoidance of surface adhesion of the bonding-partner.

Author Contributions: Conceptualization, M.W.; Formal analysis, M.W.; Funding acquisition, M.W. and D.D.; Investigation, M.W.; Methodology, M.W.; Resources, D.D.; Supervision, D.D.; Visualization, M.W.; Writing—original draft, M.W.; Writing—review \& editing, M.W. All authors have read and agreed to the published version of the manuscript.

Funding: The authors would like to thank the German Research Foundation (DFG) for funding this work within the project DFG-432470536 "Joining by using pin-like structures in welding processes".

Institutional Review Board Statement: Not applicable.

Informed Consent Statement: Not applicable.

Data Availability Statement: Not applicable.

Acknowledgments: The authors would also like to thank the BASF AG, the Evonik Industries AG and the Sabic Europe B.V. for providing the used materials.

Conflicts of Interest: The authors declare no conflict of interest.

\section{References}

1. Westkämper, E.; Löffler, C. Strategien der Produktion-Technologien, Konzepte und Wege in Die Praxis; Springer: Berlin/Heidelberg, Germany, 2016.

2. Concil Directive (EC) 2000/53/EC of the European Parliament and of the Council of 18 September 2000 on End-of Life Vehicles; European Council: Brussels, Belgium, 2000.

3. Rotheiser, J. Joining of Plastics-Handbook for Designers and Engineers; Hanser: München, Germany, 1999.

4. DVS-Deutscher Verband für Schweißen und verwandte Verfahren. Taschenbuch DVS-Merkblätter und -Richtlinien, Band 68/4-Fügen von Kunststoffen, 18, Überarbeitete und Erweiterte Auflage, Fachbuchreihe Schweißtechnik Band 68/IV; DVS Media GmbH: Düsseldorf, Germany, 2020.

5. Habenicht, G. Kleben. Grundlagen, Technologie, Anwendungen mit 37 Tabellen, 6th ed.; Springer: Berlin, Germany, 2009.

6. Ehrenstein, G.W. Handbuch Kunststoff-Verbindungstechnik; Hanser: München, Germany, 2004.

7. Hopewell, J.; Dvorak, R.; Kosior, E. Plastics recycling: Challenges and opportunities. Philos. Trans. R. Soc. London. Ser. B Biol. Sci. 2009, 364, 2115-2126. [CrossRef] [PubMed]

8. Lu, Y. An Evaluation and Development of Bonding Technologies for Rapid Disassembly of Automotive Vehicles. Ph.D. Thesis, Oxford Brookes University, Oxford, UK, 2015.

9. Essig, O.; Hartweg, M.; Keller, M.; Tomaschko, S. Methods and Apparatuses for Detaching Components Adhesively Bonded to One Another. U.S. Patent US6716297B2, 6 April 2004.

10. Banea, M.; da Silva, L.; Campilho, R. An overview of the technologies for adhesive debonding on command. Weld. Equip. Technol. 2013, 24, 11-14.

11. Malnati, P. Reversible Multi-Material Adhesive Bonds. Available online: https://www.compositesworld.com/articles/reversiblemulti-material-adhesive-bonds (accessed on 13 November 2017).

12. Haq, M.; Koricho, E.; Khomenko, A.; Gerth, R.; Drzahl, L. Tailorable Adhesives for Multi-material Joining, Facile Repair and Re-assembly. In Proceedings of the American Society for Composites 30th Technical Conference, East Lansing, MI, USA, 28-30 September 2015.

13. Wolf, M.; Kleffel, T.; Leisen, C.; Drummer, D. Joining of Incompatible Polymer Combinations by Form Fit Using the Vibration Welding Process. Int. J. Polym. Sci. 2017, 2017, 6809469. [CrossRef]

14. Wolf, M.; Drummer, D. Influence of the Structuring-Tool Geometry on Form-Fit Joining by Use of Pin-Like Structures in Vibration Welding. Procedia Manuf. 2020, 47, 375-382. [CrossRef]

15. Wolf, M.; Drummer, D. Design criteria for the pin-foot ratio for joining adhesion-incompatible polymers using pin-like structures in vibration welding process. J. Polym. Eng. 2021, 41, 873-882. [CrossRef]

16. Wolf, M.; Hertle, S.; Drummer, D. Influence of the thermomechanical properties on the joining of adhesion incompatible polymers by form-fit using the vibration welding process. Express Polym. Lett. 2019, 13, 365-378. [CrossRef] 
17. BASF SE. Product Information Ultramid@-A3K. Available online: https://documents.basf.com/8c1cc60248e98198abfcbfb4b73d5 b78eae0c0c4?response-content-disposition=inline (accessed on 8 April 2021).

18. Sabic. Sabic®PP 505P. Available online: https://www.sabic.com/en/products/documents/sabic-pp_505p_global_technical_ data_sheet/en (accessed on 8 April 2021).

19. Röhm GmbH. Product Informatio-Plexiglas®7N. Available online: https://www.plexiglas-polymers.com/en/plexiglas7n?file=files/assets /04-molding_compounds/plexiglas-polymers/downloads/en/product-information/PLEXIGLAS/7N/ PLEXIGLAS\%207N_EN.pdf (accessed on 8 April 2021).

20. Owens, D.K.; Wendt, R.C. Estimation of the Surface Free Energy of Polymers. J. Appl. Polym. Sci. 1969, 13, 1741-1747. [CrossRef]

21. Wu, S. Polymer Interface and Adhesion; Marcel Dekker, Inc.: New York, NY, USA, 1996.

22. Deutsches Institut für Normung (DIN). Kunststoffe-Bestimmung der Viskosität von Polymeren in Verdünnter Lösung Durch ein Kapillarviskosimeter-Teil 3: Polyethylen und Polypropylen (DIN EN ISO 1628-3:2010); Deutsches Institut für Normung (DIN): Berlin, Germany, 2010.

23. Deutsches Institut für Normung (DIN). Kunststoffe; Bestimmung der Viskositätszahl und der Grenzviskositätszahl; Teil 6: Methylmethacrylatpolymere (DIN EN ISO 1628-6:1990-02); Deutsches Institut für Normung (DIN): Berlin, Germany, 1990.

24. Deutsches Institut für Normung (DIN). Kunststoffe-Polyamide-Bestimmung der Viskositätszahl (DIN EN ISO 307:2019); Deutsches Institut für Normung (DIN): Berlin, Germany, 2019. 